\title{
Training simulation system for substation operation
}

- Nguyen Van Liem

- Dang Tuan Khanh

- Ho Thanh Phuong

- Nguyen Hoang Minh Tuan

- Tran Dinh Bien

Ho Chi Minh city University of Technology, VNU-HCM, Vietnam

- Duong Thanh Nhan

Tay Ninh Power Company

(Manuscript Received on July 15, 2015, Manuscript Revised August 30, 2015)

\begin{abstract}
This paper reports the development of a substation training simulation system. The simulation system operates on the basic of the combination of three software including Vijeo Designer, Unity Pro and Matlab. The first two software are used to simulate the Human Machine Interface (HMI) and Remote terminal Unit/Programmable Logic Controller ((RTU/PLC), respectively. The third software, Matlab, calculates parameters of different
\end{abstract}

operating conditions of the substation. The system has been designed as a training device which allows users to gain hands on experience in relation to substation operation. It is also used as a tool to assess and enhance the skills of current substation operators. This simulation system is the first of its kind to be developed and applied in Vietnam.

Keywords: training simulation system, substation operation, Unity Pro, Vijeo Designer.

\section{INTRODUCTION}

Operation of a substation is one of the central and important activities of power system operation, in which a misoperation of an unqualified operator may lead to a serious fault in the power system. Therefore, the training of operators who can operate properly a substation is a critical. This is not only to ensure the safety of personnel and equipment but also to guarantee reliability of the power system. However, due to the continuity and importance in the electricity production, the training to the trainee cannot be performed on the actual system, and creating manmade accidents to help the trainee to observe and handle is absolutely prohibited.

The training of substation operators in Vietnam, so far, is mainly based on traditional and passive education, i.e., learners gain knowledge in relation to substation operation through the teaching of instructors using textbooks and other documents. The learners cannot practice and apply their knowledge in a practical substation 
due to the requirement to ensure uninterrupted power supply and avoid damaging equipment. The key drawback of this training system is that the learners cannot gain any experience related to operation of a practical substation. Therefore, the simulation system is one of the best methods to cater for the training of substation operators.

Simulation is an effective research and training method. It has been applied in various fields and achieved much success. In the aviation sector [1-2], for example, the simulation has been used for training pilots, testing routes, improving existing design. A typical example of using simulation technique is that of using a virtual cockpit to simulate gold routes [3]. In the area of drivers training [4-5], the teaching programs based on simulation technique implemented in Vietnam have been put into use to improve teaching quality and reduce the learning time [67].

The advantage of simulation is the flexibility to set up the conditions as well as vary parameters which are unlikely or difficult to perform in reality due to the constraints of safety operation. The other advantage is that of avoiding any damage to expensive equipment due to wrong action. Therefore, the application of simulation in power system has been researched and developed. In training of power system operation, the first simulation application was in power plants [8-9] and then the simulations have been extended to substations [10-14].

The above mentioned simulation models were a combination of hardware and software, in which control panels are the real ones containing buttons, switches and meters while parameters displaced in the control panels are calculated using appropriate software [9-10]. By using this model, the users can perform manipulations directly similar to operation of the real system. However, the cost of hardware is not cheap and the hardware requires the space to be installed.
Moreover, there is still possibility of equipment failure due to malfunction. Therefore, the models of this type have gradually replaced by models based purely on PC and software.

In software-based models, all substation devices including the control screen, protection screen, single-line diagram and so on are simulated by software, and operation of equipment such as transformers, busbars, disconnecting switches, circuit breakers, capacitors are also completed by the corresponding software of the computer.

The objective of the present paper is to develop a software-based substation training simulation system, which, for the first time, combine three different software including Vijeo Designer, Unity Pro and Matlab to simulate the operation of a substation. Vijeo Designer is a state-of-the-art software application that allows to create Human Machine Interfaces (HMI). It also provides all the tools needed to design a project, from the acquisition of data to the creation and display of animated drawing. Unity Pro is a powerful programming software for a programmable logic controller (PLC). It supports PLC simulation with the tool of PLC/Simulation Mode. Matlab is used as programming software to calculate the parameters of substation in different operating conditions. The simulation system can be used to train future substation operators as well as assess and improve skills of current substation operators. It can also be used by researchers in the area of substation operation.

\section{PRACTICAL SUBSTATION OPERARTION}

The operation of a practical substation nowadays is based on supervisory control and data acquisition (SCADA) system. Structure of a mini SCADA applied for operating a substation is given in Fig. 1 below. 
The SCADA system for operation of a substation consists of three basic parts: Human Machine Interface (HMI), Remote Terminal Unit (RTU) and main equipments of substation.

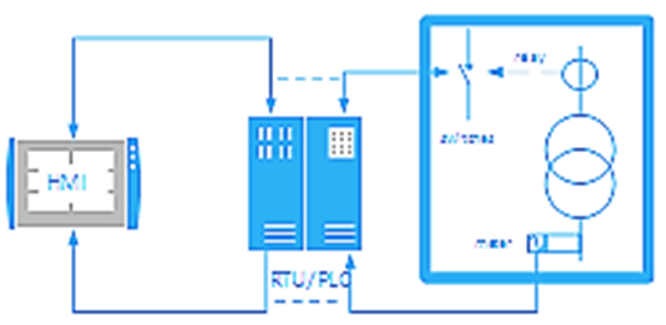

Fig. 1: Structure of simple SCADA system

HMI provides an interface between users and machine. At the substation, this is the operating screen showing the single-line diagram of the substation, the online operating parameters, the switching status, alerts, operating history. This also provides functions of manipulation and control on the screen. The HMI runs on the computer at the substation. The HMI connects directly, or via a switch, to the RTU.

RTUs are terminals for signal communication and control equipment. They communicate and transfer signals between the HMI and equipment of the substation. In practice, Programmable Logic Controller (PLC) is used to work as RTU. For this reason, it is referred to as RTU / PLC.

Main equipment are power transformers, busbars, switching devices such as Circuit Breakers (CBs) and Disconnecting Switches (DSs), measurement, control devices with communication support for monitoring and remote control. These devices are connected to the RTU to communicate data and receive control signals.

\section{DESIGN OF TRAINING SIMULATION SYSTEM FOR SUBSTATION OPERATION}

Against background of the operation of a practical substation presented in Section 2, this section describes the design of a training simulation system for substation operation as given in Fig. 2.

The design is based on the combination of three specialized software which are Vijeo Designer, Unity Pro and Matlab. All of them run on only one computer. Three software play the role of three parts of a substation operation mentioned in Section 2.

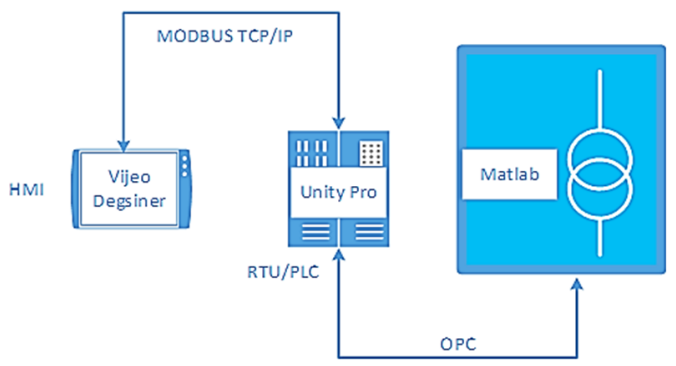

Fig. 2: Model for simulation of substation operation

The Vijeo Designer is used to design HMI screen in which single-line diagram, online operating parameters, close/open status of CBs and DSs, position of transformer tap changers and pop-up alarm/error massage are displayed. The switch setting functions of the Vijeo Designer allow to directly close/open CBs and DSs as well as change the position of transformer tap changers. The functions of animation help to show the operating status of CBs and DSs as well as the position of transformer tap changers. The history of events, alarms and operating parameters can also be created by using the tool of alarm of Vijeo Designer. A typical HMI designed for simulation of substation operation is illustrated in Fig. 3 below. 


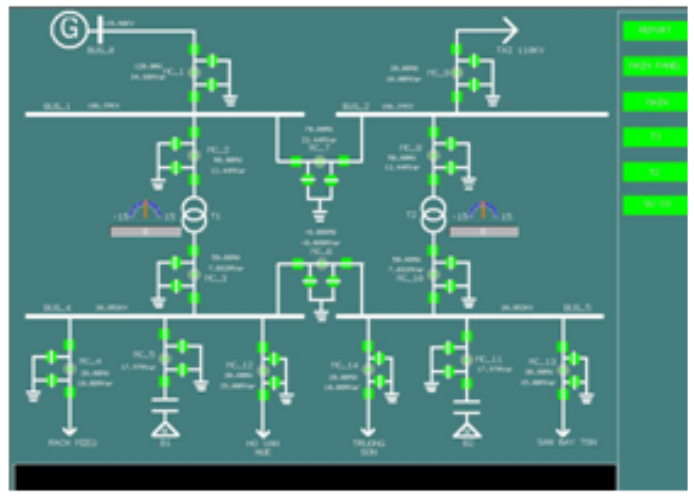

Fig. 3: HMI developed for simulation of substation operation

The Unity Pro is used for RTU / PLC communication and signal processing using PLC/Simulation Mode. Virtual PLCs provided by Unity Pro, which are used in the design, can have all functions of an actual PLC such as hardware variables, connections and modules. The required program used in substation operation simulation can be developed using the standard of IEC611313 and then loaded on the virtual PLCs. The main function of PLC is signal processing for control and communication between HMI and calculated program such as Matlab.

Matlab is used to calculate online operating parameters of the substation in different operation conditions. The calculated operating parameters such as voltages, currents, powers, and transformer oil temperatures are displayed on the HMI. In practical substations, these parameters are displayed on meters whose inputs are connected to instrumental transformers.

In order for the above software to communicate to each other during the simulation process the following communication modes have been chosen. The communication between Vijeo Design and Unity Pro is based on protocol of Ethernet Modbus TCP/IP with default address of the virtual PLC being of 127.0.0.1, Port 502. Between Unity Pro and Matlab, the communication is performed via OPC (Open Process Control) of Matlab.

\section{COORDINATION BETWEEN THREE SOFWARE}

As the design uses simultaneously three software to simulate the substation operation, an issue in relation to coordination between them has to be addressed. This section presents the coordination between Vijeo Designer (HMI), Unity Pro (PLC) and Matlab.

The coordination between the three software is illustrated in Fig. 4. Any manipulation such as close/open of CBs and DSs can be done on HMI using a mouse of PC. If the action is not acceptable or not satisfied the condition of interlock then the alarm/message is displayed on the HMI; otherwise, the action leads to the updating the values of variables and changing the status of equipment related to the manipulation on the HMI. The statuses of all equipment of the substation are then transferred to the PLC of Unity Pro. Through the read function of OPC, Matlab obtains values of status variables from PLC and then updates the statuses of all witching equipment, modifies matrix Ybus of the system, and calculates operating parameters. The parameters such as voltage, current, power, temperature are now written to PLC through the write function of OPC, and displayed on the HMI. In order to ensure the synchronization of the whole simulation process, the calculation of Matlab is repeated continuously, so that any change in substation operating condition can be calculated and updated on HMI.

\section{PERFORMANCE OF TRAINING SIMULATION SYSTEM FOR SUBSTATION OPERATION}

The design has been implemented and installed on a PC. The substation used in the simulation system consists of two power transformers $110 / 22 \mathrm{kV}$, one $110 \mathrm{kV}$ feeder, four 
$22 \mathrm{kV}$ feeders and two $22 \mathrm{kV}$ capacitor banks. The simulation system can be used to simulate not only normal but abnormal conditions as well. In normal condition modes, the users can energise or disconnect transformer, feeder and capacitor bank by closing or opening the corresponding CBs and DSs. In order to regulate voltages, the users can adjust the position of transformer tap changers.
The HMI in a normal condition is given in Fig. 5. In faulted conditions, a fault can be created by the software. Under this fault, all relais which protect the faulted element operate and corresponding CBs are opened to isolate the faulted equipment from the rest system. The HMI in faulted condition is shown in Fig. 6.

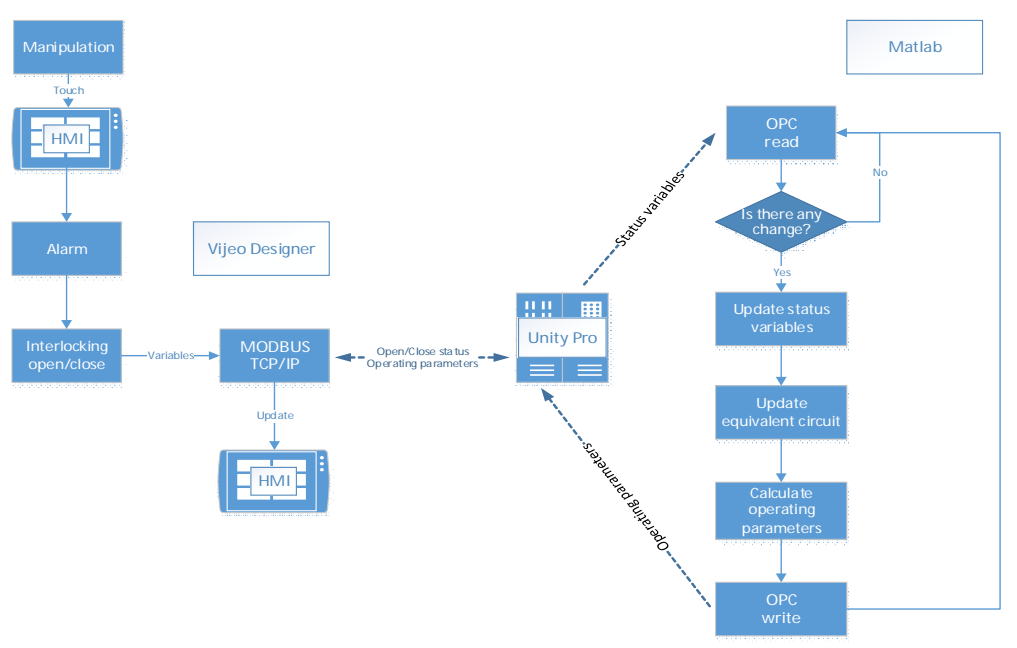

Fig. 4: Coordination between Vijeo Designer, Uni Pro and Matlab

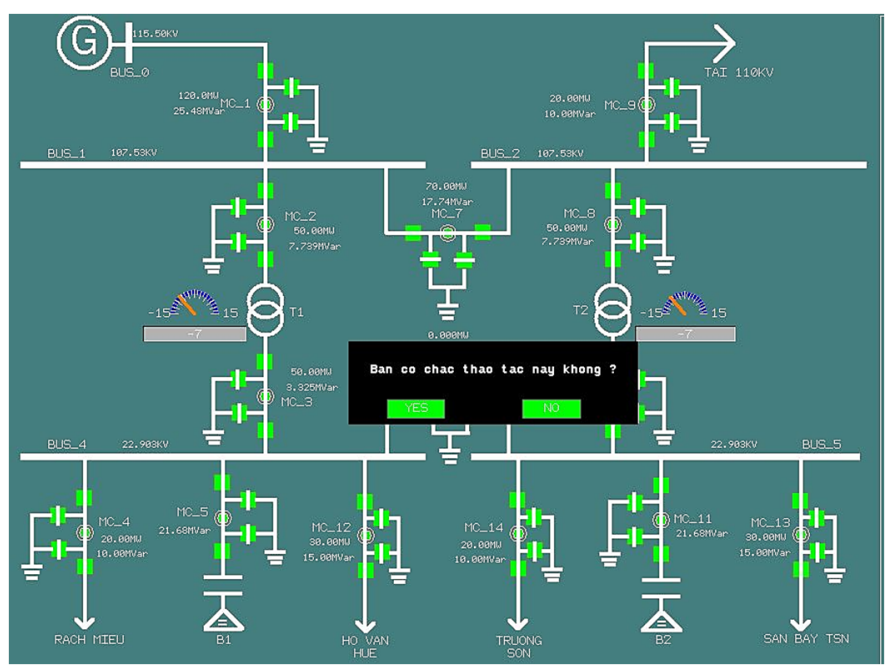

Fig. 5: HMI for normal operating condition 


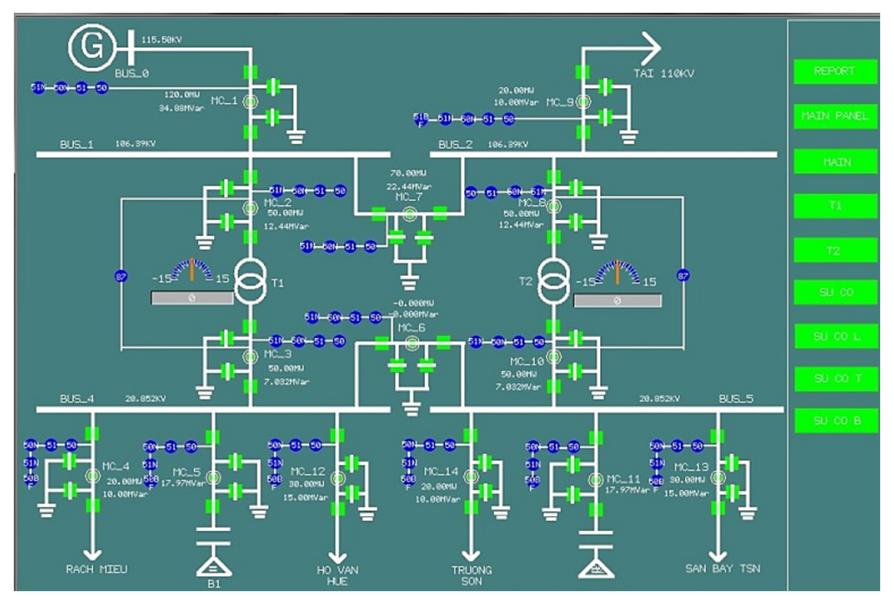

Fig. 6: HMI for abnormal operating condition

\section{CONCLUSIONS}

The software-based substation training simulation system has been designed and implemented to facilitate the training of substation operators. The design, for the first time, combines three different software including Vijeo Designer, Unity Pro and Matlab to simulate the operation of a substation. The designed simulation system can be used to train effectively future substation operators, assess and enhance skills of current substation operators in the area of recognition and prosessing faults. The simulation system can also be adopted by reseachers in order to develop substation operation procedure and fault processing.

\section{ACKNOWLEDGEMENTS}

This research is funded by Ho Chi Minh City University of Technology under grant number TĐ७-2013-72.

\section{Hệ thống mô phỏng huấn luyện vận hành trạm biến áp}

- Nguyễn Văn Liêm

- Đặng Tuấn Khanh

- Hồ Thanh Phương

- Nguyễn Hoàng Minh Tuấn

- Trần Đình Biên

Trường Đại học Bách Khoa, ĐHQG-HCM, Việt Nam

- Dương Thành Nhân

Công ty Điện lực Tây Ninh 


\section{TÓM TÁT}

Bài báo trình bày việc xây dựng hệ thống mô phỏng vận hành trạm biến áp. Hệ thống được thiết kế trên cơ sở phối hợp ba phần mềm bao gồm Vijeo Designer, Unity Pro và Matlab. Hai phần mềm đầu tiên được sử dụng để mô phỏng giao diện người máy (HMI) và thiết bị đầu cuối/bộ điều khiển logic lập trình (RTU/PLC), tương ưng. Phần mềm thứ ba, Matlab, tính toán thông số của các chế độ vận hành khác nhau của trạm biến áp. Hệ thống được thiết kế như thiết bị huấn luyện cho phép người sử dụng tích lũy kinh nghiệm thực tế liên quan đến vận hành trạm biến áp. Hệ thống cũng có thể được sử dụng như công cư đề đánh giá và nâng cao kỹ năng của các vận hành viên đang vận hành trạm biến áp. Hệ thống mô phỏng được trình bày trong bài báo là hệ thống mô phỏng vận hành trạm biến áp lần đầu tiên được xây dựng và ứng dụng tại Việt Nam.

Từ khóa: hệ thống mô phỏng huấn luyện, vận hành trạm biến áp, Unity Pro, Vijeo Designer.

\section{REFERENCES}

[1]. J. Chao, J. Shen, N. He, "Space flight simulation training technology research project", 2010 Second World Congress onSoftware Engineering, vol. 2, pp. 53-61, December 2010.

[2]. W. Wang, D. Li, C. Liu, "Fixed-wing Aircraft Flight Simulation and Training System Interactive Based onXNA" 2013 International Conference Reality and Visualisation onVirtual (ICVRV), pp. 191-198, September 2013.

[3]. http://mt.gov.vn/Default.aspx?tabid=26\&cati $\mathrm{d}=24 \&$ articleid $=22611$.

[4]. CP Maria, Evangelos DB, AT AIKATERINI, "ADAS in driving simulation module for training young drivers," Power and Energy Engineering Conference, 2009. APPEEC 2009. Asia-Pacific.

[5]. F. Jing, X. Lirong, "Intelligent Driving Simulation Training System Based on Virtual Reality", Intelligent Transportation Systems, 2003. Proceedings. 2003 IEEE, vol. 1, pp. 2730, October, 2003.

[6]. http://www.cic.edu.vn/bai-viet1457/Hethong-mo-phong-lai-xe-oto-VehicleSimulator.html.

[7]. http://automation.net.vn/Tu-dong-hoa-dandung/Giai-phap-hieu-qua-trong-day-va-hoclai-oto-He-thong-mo-phong-lai-xe.html.
[8]. V. Kola, A. Bose, PM Anderson, "Power plant operator training simulators for models", IEEE Transactions on Power Systems, vol. 4, issue 2, pp. 559-565, May 1989.

[9]. G. Yan, W. Li, "Summary of substation simulation training system", Power Engineering Conference, 2009, APEEC 2009. Asia-Pacific.

[10].H. Shiota, Tamenaga Y., T. Tsuji, K. Dan, "Development of training simulator for power system operators", IEEE Transactions on Power Apparatus and Systems, Vol. PAS102, No. 10, October 1983

[11].S. Fang, "Application and development of substation simulation training system", High Votage Engineering, vol. 31, no. 4, pp. 79-81, April 2005.

[12].A. Okapuu-von, R.J. Marceau, A. Malowany, Design and operarion operation of a virtual reality training system ", IEEE Trans. On Power system, vol. 11, pp. 1585 to 1591.1999.

[13].F. Jiang, W. Lai, Q. Gong, J. Jiang, "Application of virtual reality training system in substation and" High Votage Engineering, vol. 31, no. 7, pp. 68-70, July 2005.

[14].E. Arroyo, JL Los Arcos, "SRV: A virtual reality to electrical substaions applicatiopn operation training", International Conference on Multimedia and System Compoutiong Proceedings, 1, pp. 835-839, 1999 